\title{
De la cuota a la democracia paritaria: estrategias partidistas y representación política de las mujeres en España
}

Tània VERGE

\section{Introducción}

$\mathrm{E}$ spaña se ha convertido en los dos últimos años en un referente mundial en diversas políticas de igualdad, entre las que no ha pasado desapercibido el impulso a la representación política de las mujeres. En la actualidad, cuenta con uno de los pocos gobiernos paritarios que existen en el mundo en el cual las mujeres ocupan ocho de los dieciséis ministerios del actual gabinete, además de la Vicepresidencia del Gobierno, tras dos décadas con un número de ministras que oscilaba entre tres y cinco $^{1}$. Por otro lado, en el Congreso de los Diputados están presentes un 36 por ciento de diputadas, un porcentaje que ubica a España en el séptimo puesto del ranking mundial, según datos de la Unión Interparlamentaria (IPU), y que le acerca a pasos acelerados a la paridad. ¿Qué ha hecho que una joven democracia como la española supere en este aspecto por un amplio margen a democracias tan longevas y consolidadas como la alemana, la británica o la francesa?

La mayoría de los trabajos que estudian la representación política de las mujeres carecen de la profundidad y evidencia empírica deseables porque se hacen a partir de datos externos, debido a las dificultades encontradas a la hora de obtener información sobre cuestiones organizativas que, en la mayoría de las veces, sólo disponen los propios partidos. Y más escasos aún son los estudios que superan el enfoque descriptivo y que analizan los documentos partidistas para explicar las motivaciones de los cambios

1. De 1982 a 1986 no hubo ninguna ministra en el Gobierno socialista. De 1988 a 1991 hubo dos ministras y de 1993 a 1995 fueron tres. En el primer Gobierno del Partido Popular (1996-2000) empezaron cuatro ministras y terminaron dos. En el segundo mandato popular (2000-2004) el Gobierno inicial contaba con tres ministras pero finalizó con cinco (Instituto de la Mujer, 2004). 
introducidos. El artículo plantea pues superar estas deficiencias a través del seguimiento de las estrategias adoptadas por los partidos políticos españoles de ámbito estatal, el Partido Socialista Obrero Español (PSOE), el Partido Popular (PP) e Izquierda Unida (IU), bajo una perspectiva diacrónica que abarca el intervalo comprendido entre las primeras y las últimas elecciones celebradas en el período democrático 1977-2004.

La demanda de igualdad política se dirige a los partidos políticos puesto que las instituciones representativas se configuran a través de ellos; dicho de otro modo, son los gate-keepers de los cargos electos (Ryder, 1996: 110; Young, 2000: 150). Ésta ha sido tradicionalmente una demanda apoyada por los partidos de izquierda. En España, el PSOE e IU reflexionaron, desde finales de la década de los ochenta, sobre un motivo de descontento entre ciertas capas de la sociedad: las mujeres no podían seguir viendo como legítimas unas decisiones políticas que tomaban mayoritariamente los hombres en las instituciones públicas en una evidente desproporción respecto al peso demográfico de hombres y mujeres en la población, ni tampoco las decisiones adoptadas por los órganos ejecutivos de los partidos donde la presencia de la mujer era meramente testimonial. Por ello, introdujeron un nuevo mecanismo en sus listas internas y electorales que entendían podía "revitalizar la democracia": la cuota femenina.

Sin embargo, con la difuminación de la relación entre el voto femenino y el apoyo a partidos de derechas (Uriarte, 1997: 26; Lovenduski y Norris, 1993), estos partidos se han visto también obligados a incorporar en sus listas y cargos a un número creciente de mujeres como incentivo para atraer el voto de las mujeres (Ruiz Jiménez, 2002: 68; Phillips, 1998: 224), a pesar de que rechacen la introducción de medidas de discriminación positiva por considerar que el género no puede imponerse al mérito y a la capacidad como criterio de elección de candidatos y candidatas.

Más allá de la valoración de la idoneidad de la cuota por parte de los partidos, en España, en las dos últimas décadas, se ha producido un considerable incremento de la presencia de las mujeres en puestos de responsabilidad política. La representación femenina en el Congreso de los Diputados se ha más que quintuplicado en el PSOE de 1977 a 2004, IU ha pasado de no tener ninguna diputada en 1986 a constituir el 40 por ciento de su Grupo Parlamentario en 2004, y en el PP el número de mujeres en este período se ha triplicado, una tasa de crecimiento que no puede ser infravalorada, a pesar de que las mujeres no alcanzan el 30 por ciento de su representación parlamentaria (véase la Tabla 1). Este incremento podría haber debilitado la introducción de nuevas estrategias ya que, de seguir esta tendencia, el porcentaje de mujeres en la vida política igualaría al de los hombres de forma natural en unos años (o décadas). Con todo, los partidos de izquierda han seguido impulsando la democracia paritaria con el apoyo de asociaciones feministas nacionales y de diversas organizaciones internacionales. 
Tabla 1

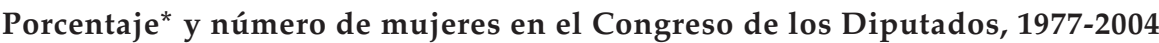

\begin{tabular}{|c|c|c|c|c|c|c|c|c|c|}
\hline Legislatura & $77 / 79$ & $79 / 82$ & $82 / 86$ & $86 / 89$ & $89 / 93$ & $93 / 96$ & $96 / 00$ & $00 / 04$ & $04 / 08$ \\
\hline PSOE & 6,8 & 5,0 & 6,9 & 7,1 & 17,1 & 17,6 & 27,7 & 36,8 & 46,3 \\
\hline $\mathrm{PPa}$ & 6,3 & 11,1 & 0,9 & 5,9 & 10,4 & 14,9 & 14,3 & 25,1 & 28,4 \\
\hline $\mathrm{IU}^{\mathrm{b}}$ & 15,8 & 8,7 & 0,0 & 0,0 & 11,0 & 22,0 & 33,0 & 25,0 & 40,0 \\
\hline TOTAL CONGRESO & 6,0 & 5,0 & 5,9 & 8,4 & 13,9 & 16,0 & 24,0 & 28,3 & 36,0 \\
\hline Partido en el Gobierno & $\mathrm{UCD}^{\mathrm{c}}$ & UCD & PSOE & PSOE & PSOE & PSOE & PP & PP & PSOE \\
\hline
\end{tabular}

Fuente: Elaboración propia.

*Al constituirse la Cámara.

a Los datos se refieren a las distintas etiquetas con las que ha concurrido el partido (Coalición Democrática, Alianza Popular, Coalición Popular y Partido Popular).

b Los datos se refieren al Partido Comunista de España (PCE) de 1977 a 1982 y a IU de 1986 a 2004.

c Unión de Centro Democrático.

¿Cuáles son las estrategias que han implementado los partidos en el transcurso de las dos últimas décadas? ¿A qué motivaciones responden? Para responder a la primera pregunta se aplicará a las tres formaciones políticas españolas de ámbito estatal el esquema planteado por Lovenduski y Norris (1993: 8), según el cual los partidos pueden adoptar estrategias retóricas, de acción positiva o de discriminación positiva para alentar una mayor presencia femenina ${ }^{2}$.

Son estrategias retóricas aquellas que suponen el apoyo a esta reivindicación en los programas electorales, en las resoluciones congresuales, o bien en las declaraciones públicas de los dirigentes del partido. El compromiso con la representación de las mujeres en la retórica de un partido puede ser el inicio de un proceso que conduzca a políticas de inclusión más amplias en la propia organización e incluso a la introducción de esta demanda en la agenda política. Por otro lado, los partidos pueden aplicar estrategias de acción positiva que incluyen programas de formación para afiliadas y/o candidatas, la creación de secciones específicas de mujeres y el establecimiento de relaciones con organizaciones feministas, o campañas para una representación política con equilibrio de género. En este caso, es preciso analizar la estructura organizativa del partido y las actividades formativas y divulgativas cuyo objetivo sea la igualdad

2. Aunque suelen identificarse las expresiones "acción positiva" y "discriminación positiva", existe un matiz importante entre ellas: mientras que las primeras favorecen a un grupo determinado sin perjudicar directamente a nadie, las segundas tienen consecuencias sobre otros. Así, la cuota supone conceder una reserva de puestos a un grupo en detrimento del "cupo" del que disfrutaba otro colectivo. 
en la representación. Por último, los partidos pueden poner en práctica una estrategia de discriminación positiva a través de la reserva de puestos en los órganos ejecutivos del partido o en las listas electorales.

En segundo lugar, es preciso analizar los factores externos e internos que han llevado a los partidos a incrementar la presencia de las mujeres en los ámbitos de poder orgánico y público. Prestaremos una atención especial a determinados factores de la competición política como las rivalidades interpartidistas, los resultados electorales y la cambiante distribución por partidos del electorado femenino. A nivel interno, nos interesaremos por el poder orgánico de las mujeres, por el apoyo que las cúpulas de los partidos hayan mostrado a esta reivindicación y por la presión realizada por organizaciones de mujeres vinculadas a los partidos.

El artículo se desarrolla en tres partes diferenciadas. Las tres primeras secciones examinarán, respectivamente, las estrategias retóricas, de acción y de discriminación positiva desarrolladas por los tres partidos españoles de ámbito nacional a través del estudio de los programas electorales y de las resoluciones de sus congresos internos, de las modificaciones estatutarias introducidas, así como de otros documentos políticos elaborados por los partidos durante el período 1977-2004. También se incluirán reflexiones efectuadas por dirigentes y representantes de las tres formaciones políticas en diversas entrevistas en profundidad y aquellas declaraciones de dirigentes y cargos públicos del partido recogidas en la prensa nacional. En el cuarto apartado se estudiarán los factores que han empujado a los partidos a implementar las diferentes estrategias y, por último, se presentarán las conclusiones y principales hallazgos.

\section{Estrategias retóricas}

\section{Estrategias retóricas aplicadas por el PSOE}

El discurso por la igualdad de la mujer estuvo ya presente en los primeros congresos celebrados en período democrático. En el XXVIII Congreso (1979) se valoró la participación de las mujeres en los órganos del partido como insatisfactoria y se planteó la necesidad de incorporar la problemática de la mujer en las propuestas del partido como símbolo de la identidad de la izquierda y como elemento diferenciador del programa de la derecha ${ }^{3}$ (PSOE, 1979: 20). El XXIX Congreso (1981) volvía a reconocer la escasa incidencia política de la mujer, tanto en el partido como

3. Hasta finales de los años setenta, el feminismo había sido calificado despectivamente por los propios partidos de izquierda como un movimiento "burgués". Incluso en 1978, Alfonso Guerra, Vicesecretario General del PSOE, afirmaba que las mujeres tenían razones para reivindicar ciertos derechos pero que los movimientos feministas eran absolutamente reaccionarios dado que constituían una desviación respecto al objetivo de construcción de la democracia y del socialismo (Threlfall, 1996: 146). 
en los órganos de representación institucional. De hecho, la igualdad política se fijará no sólo como meta del partido sino como "condición imprescindible para la existencia de la propia democracia" (PSOE, 1981: 233). No obstante, los programas electorales generales de estos años hacen énfasis en el impulso de diferentes medidas para conseguir la igualdad de oportunidades en la educación y en el trabajo, en la despenalización del aborto o en la expansión de los servicios sociales, pero no mencionan la participación de las mujeres en la vida política.

El XXX (1984) y XXXI Congreso (1988) encargarán de nuevo a la dirección tanto la potenciación de la presencia y el protagonismo de las mujeres en el partido como en los puestos de responsabilidad pública (PSOE, 1984: 90; PSOE, 1988a: 83), además del esfuerzo por romper en el seno de la organización la concepción de que los temas de género eran un problema sectorial que afectaba sólo a las mujeres (PSOE, 1988a: 18). En 1986, el programa electoral incluye el compromiso de fomentar una mayor participación de las mujeres en todos los niveles de responsabilidad y de educar a la sociedad, en general, en la igualdad y a las mujeres, en particular, en la participación (PSOE, 1986: 82). En 1989, además de la participación política, se introduce la idea de que, para conseguir la igualdad en el acceso a puestos de responsabilidad, resulta básico el reparto de las responsabilidades familiares y el desarrollo de servicios sociales para el cuidado de personas dependientes (PSOE, 1989: 66).

El XXXII Congreso (1990) destaca en sus conclusiones la exigencia creciente de una mayor presencia y participación en los puestos de responsabilidad y decisión para superar el agravio que supone la infrarrepresentación institucional de la mujer (PSOE, 1990: 40). En 1993, encontramos por primera vez un apartado destinado a "aumentar el protagonismo y la participación social y política de las mujeres" para corregir este "déficit democrático" (PSOE, 1993: 60). En este sentido, el XXXIII Congreso (1994) afirmaba que la representación de la mujer era una demanda insatisfecha que seguía siendo un reto para el partido, para la sociedad y para la propia democracia:

Una sociedad democrática no puede permitir la exclusión o la marginalidad política de las mujeres cuando su sistema está basado en la igual soberanía de todas las personas. El desarrollo de la democracia, como el avance hacia la igualdad social, no se entiende sin la presencia de las mujeres y los valores que éstas aportan. Sin las mujeres no es posible un desarrollo en profundidad de la democracia, porque sería prescindir de la participación de la mitad del género humano (PSOE, 1994a: 91).

Las propuestas electorales presentadas en 1996 incluyen el objetivo de conseguir una presencia paritaria en los órganos representativos y el fortalecimiento del asociacionismo femenino (PSOE, 1996: 66-68). En el XXXIV Congreso (1997) se asumirá de forma decidida la democracia paritaria. En las resoluciones se adjunta una declaración aportada por la Federación de Mujeres Progresistas (FMP), Por un nuevo contrato social 
mujeres-hombres: compartir las responsabilidades familiares, el trabajo y el poder, en la cual se reclama la participación compartida del poder y la incorporación de la contribución de las mujeres en las ideas, valores y modos de actuación de las instituciones. Según el partido, "la presencia igualitaria de las mujeres en las instituciones generará decisiones públicas más cercanas al sentir de la sociedad" (PSOE, 1997: 95).

En los dos últimos congresos celebrados en los años 2000 y 2004, se seguirá apostando por la expansión de la democracia paritaria a todos los terrenos como un mecanismo de "revitalización" y de "mejora" de la democracia (PSOE, 2004a: 73). En estos años se multiplican las propuestas a favor de la igualdad en la representación en los programas electorales, siendo la principal novedad la reforma de la Ley Orgánica del Régimen Electoral General (LOREG) para garantizar la presencia equilibrada en las listas de candidatos -ni más del 60 ni menos del 40 por ciento de hombres o mujeres (PSOE, 2000: 25)-, el compromiso con la configuración de un gobierno paritario, la eliminación de la discriminación de la mujer en el acceso a la jefatura del Estado (que supone la reforma de la Constitución) y la aplicación de medidas para incrementar la presencia de las mujeres en la administración pública (PSOE, 2004b: 93).

\section{Estrategias retóricas aplicadas por IU}

La coalición Izquierda Unida hereda desde su constitución la tradición feminista de las mujeres comunistas del Partido Comunista de España (PCE), quienes habían conseguido que, a finales de los años setenta y principios de los ochenta, el PCE fuera el partido que más se volcara a nivel programático en el apoyo a la participación social y política de las mujeres ${ }^{4}$ Los programas electorales generales de 1977, 1979 y 1982 guardan silencio al respecto de la participación política de las mujeres, pero esta ambición está ampliamente recogida en los programas municipales constituyéndose, en esos años, en la avanzadilla de esta reivindicación al comparar los programas de los tres partidos de ámbito estatal (PCE, 1977: 9; PCE, 1979: 6; PCE, 1983a: 19). Sin embargo, la participación de las mujeres en la estructura del PCE era una asignatura pendiente reconocida por la propia organización:

Para eliminar el machismo y conseguir la completa igualdad en sus filas entre la mujer y el hombre, es decisivo una política firme de promoción de dirigentes feministas y de las mujeres como dirigentes del partido, un

4. Izquierda Unida se constituyó en 1986 como una coalición de partidos y colectivos, entre los que destacaba su principal impulsor, el PCE, que se erigía en "Movimiento Político y Social". Los malos resultados electorales obtenidos por el PCE en anteriores elecciones motivó a sus líderes a buscar nuevas fórmulas de participación política y nuevas alianzas, en especial, con las organizaciones y movimientos sociales de nuevo tipo (feminismo, ecologismo, etc.). 
esfuerzo permanente por crear en el partido el ambiente necesario para que asuma plenamente su papel en la lucha por la liberación de la mujer (PCE, 1978: 18).

En esos años, las mujeres comunistas reclamaban su presencia en los órganos de dirección y alertaban de que el partido no podía seguir posponiendo estos temas ya que se estaba observando una frustración creciente entre las mujeres y una desafiliación femenina en el seno del partido (PCE, 1981: 9). En el XI Congreso (1983) se planteó la necesidad de buscar formas de militancia que tuvieran en cuenta la situación específica de la mujer y que facilitasen su participación política (PCE, 1983b: 31).

En 1986 el PCE se integra en la coalición de Izquierda Unida. Teniendo en cuenta que, en los primeros pasos políticos de IU, el 80 por ciento de sus militantes provenían del PCE, la lucha por la igualdad en la representación no podía dejar de verse reflejada. En esta línea, el programa electoral de 1986 manifestaba: "Las mujeres, que representan el 52 por ciento de la población, son olvidadas y marginadas, tanto en su representación política y parlamentaria como en su situación económica y social" (IU, 1986: 27). El apoyo a la participación de las mujeres se traduce en propuestas tales como la promoción de las organizaciones sociales feministas y la adopción por parte del Estado de "medidas ejemplificadoras" que fomenten la paridad en las organizaciones políticas y en la Administración Pública. Por otra parte, a nivel interno, se asume el compromiso de incorporar a la dirección del partido a un 25 por ciento de mujeres (IU, 1989: 66).

A partir de 1990 se considerará la participación política de la mujer como parte integrante de su liberación definitiva (IU, 1990: 37). En 1996, en el programa de las elecciones generales, IU propone que sea obligatorio para los partidos el equilibrio de género en el reparto de responsabilidades orgánicas en los partidos. En 1999 la coalición plantea de forma novedosa algunas fórmulas paritarias en la contratación funcionarial y laboral (IU, 1999: 45 y 70). Sin embargo, es a partir del año 2003 cuando el apoyo a estas medidas se reclama con mayor claridad al exigir la paridad efectiva en todos los ámbitos de representación social e institucional (IU, 2004: 66).

\section{Estrategias retóricas aplicadas por el PP}

No será hasta mediados de los años noventa cuando el partido defenderá el impulso a la participación femenina en el proceso de toma de decisiones políticas en igualdad con los hombres, aunque, como veremos más adelante, con diferencias notables respecto de los partidos de izquierda. Sin embargo, se adelanta ya una idea clave: el rechazo frontal a cualquier medida de discriminación positiva.

En el XII Congreso, celebrado unos meses antes de las elecciones generales de 1996 en las que el PP obtiene la mayoría parlamentaria, el partido 
declaraba que la "plena igualdad de la mujer en la sociedad española" era un "objetivo irrenunciable" del partido. No obstante, insistía en el siguiente posicionamiento: "No se trata de establecer unas discriminaciones legales positivas que, además de contravenir la legislación europea, pueden ser contraproducentes, sino de realizar una política activa que ponga fin a esos impedimentos" (PP, 1996a: 66). En ese mismo año se produce un salto muy importante al introducir en las propuestas programáticas el fomento del asociacionismo femenino junto a la participación de las mujeres en la esfera política y social, promoviendo su presencia en los órganos de decisión (PP, 1996b: 187). Sin embargo, al parecer la incorporación en el programa electoral obedeció a la competición electoral con los partidos de izquierda que, según el PP, habrían intentado apropiarse de esta reivindicación como estrategia mercadotécnica, aún estando lejos todavía de cumplir la igualdad en sus respectivas formaciones (PP, 1996a: 67). El objetivo de la participación política de la mujer en las instancias de decisión seguirá presente en los congresos populares posteriores. En 1999, la incorporación de más mujeres en puestos de responsabilidad política pasa a entenderse como un derecho:

Si la mujer representa la mitad del talento y de los recursos humanos de nuestro país perderíamos de nuevo el tren de la historia si se permite que estos valores sean infrautilizados o estén subrepresentados (...). Existe un evidente desequilibrio, cuantitativo y cualitativo, en la participación de las mujeres en el ámbito de toma de decisiones. Especial consideración merece el ámbito político ya que las decisiones adoptadas por los Gobiernos, Parlamentos, partidos y administraciones autonómicas afectan a la sociedad en su conjunto y más de la mitad de la población son mujeres (...). El derecho a la participación en la toma de decisiones y en el reparto de poder, es un derecho fundamental (PP, 1999: 101-103).

Con todo, el mayor énfasis en la participación política de la mujer, aunque se mantendrá como mandato congresual a la dirección del partido (PP, 2002a: 144), sólo reaparecerá de forma muy vaga en el programa electoral de 2004 (PP, 2004a: 109).

\section{Estrategias de acción positiva}

\section{Acciones positivas en el PSOE}

En enero de 1977 se creó la Comisión de estudio "Mujer y Socialismo", dependiente de la Secretaría Federal de Formación, primero, y constituyéndose, después, en vocalía de la Secretaría de Acción Social ${ }^{5}$. Esta

5. La Comisión se creó a instancia de un grupo de mujeres militantes del partido quienes también formaban parte del movimiento feminista autónomo. La Comisión nunca tuvo una participación masiva, incluso contó en sus inicios con la animadversión de no pocas compañeras de partido que en cada encuentro criticaban la autodiscriminación de las mujeres en este grupo (Fernández Felgueroso, 1990: 196). Tampoco se logró en los primeros años un apoyo especial por parte de los dirigentes del partido (Astelarra, 2005: 134). 
Secretaría ya había impulsado la creación de un área de trabajo político dedicado a la mujer que, a su vez, apoyaba al Grupo Parlamentario, mediante la preparación y la elaboración de proposiciones de ley y mociones, y la realización de campañas informativas sobre las posiciones del PSOE en temas como la regulación legal del divorcio y el aborto. En 1984, el partido decidió que una de las seis Secretarías Ejecutivas se dedicaría a elaborar, coordinar y difundir la política de mujer del partido, con el fin de impulsar una mayor participación de este colectivo en la vida social y política. La Secretaría de Participación de la Mujer, creada finalmente en septiembre de 1985, integró hasta 1990 la Secretaría de Movimientos Sociales y Participación Ciudadana, año en que se constituirá finalmente en Secretaría de Área Federal, consiguiendo así un rango mucho mayor en la estructura orgánica del partido ${ }^{6}$. En esos primeros años, los objetivos de la Secretaría consistían en la creación de grupos de trabajo y de estudio que dotaran de contenido teórico-ideológico a las actividades desarrolladas buscando la participación tanto de las militantes del partido como de mujeres no afiliadas que simpatizaban con el PSOE (PSOE, 1997: 231).

El aumento de la afiliación de las mujeres ha sido un objetivo evidente del partido a lo largo de todo el período analizado. Entre 1984 y 1988 se llevó a cabo una campaña de afiliación llamada "Cada uno, uno", a través de la cual se pretendía ampliar el número de afiliados haciendo que cada miembro del partido se responsabilizara de buscar a otra persona. En 1990, dicha campaña tuvo su extensión en otra específicamente femenina, "Cada una, una o dos" (PSOE, 1988b), la única dirigida a este colectivo entre 1976 y 1996. El objetivo era alcanzar un porcentaje de afiliación femenina del 30 por ciento, meta que no sería cubierta hasta casi quince años más tarde. Cada uno de los congresos celebrados ha seguido insistiendo en la necesidad de crecimiento en afiliadas pero esta voluntad no se ha materializado en campañas concretas. A partir de 1997 se han planteado diferentes campañas de afiliación femenina como estrategia permanente entre congresos. La afiliación femenina se ha triplicado en el transcurso de las dos últimas décadas pasando del 10,2 en 1982 al 31,6 por ciento en 2004. Por otro lado, a partir de 1996, las mujeres constituyen más de la mitad de las nuevas altas producidas cada año. También se constata que las afiliadas tienen una edad tipo menor que la de los hombres y que el porcentaje de nuevos afiliados menores de treinta años es siempre más alto entre las mujeres.

Para la consecución de sus objetivos, la Secretaría buscó la profundización de las relaciones con el movimiento feminista, el propio desarrollo de la organización de las mujeres y la promoción de la participación de las militantes socialistas en estas asociaciones para superar el distancia-

6. En 2000 pasa a denominarse Secretaría de Igualdad. 
miento entre el partido y el movimiento feminista. Dicho movimiento se había declarado autónomo e independiente de los partidos políticos, aunque en caso de permitir una afiliación simultánea, éstas se dirigían básicamente al PCE (PSOE, 1981: 233). En relación con el fortalecimiento del tejido asociativo de mujeres, la Secretaría de Participación de la Mujer se puso en contacto con varias asociaciones de mujeres próximas a la izquierda con las que constituyó en 1987 la Federación de Mujeres Progresistas con el fin de "desarrollar una estructura asociativa de mujeres para contribuir en la tarea de avanzar en una sociedad más participativa y que las socialistas 'estén' activamente en el desarrollo del tejido social" y también "para ganar esfuerzos a la tradicional hegemonía conservadora en este sector" (PSOE, 1988b: 110).

En cuanto a las actividades formativas, desde finales de los años setenta el PSOE ha impulsado la formación política tanto de las afiliadas socialistas como de las mujeres que ocupan cargos orgánicos o públicos. En el partido se entendió en un inicio, que, dado que hombres y mujeres habían sido sometidos a formas de socialización y educación diferentes, era necesario fomentar las capacidades de liderazgo femenino para situar a las mujeres en condiciones de igualdad en la participación política. El número de cursos o ciclos formativos ofrecidos ha ido aumentando progresivamente y también lo ha hecho el número de mujeres inscritas. Si hasta principios de los años noventa las mujeres representaban alrededor del 30 por ciento de los participantes de las actividades formativas, en 1996 éstas suponían ya el 52 por ciento (PSOE, 1994b y PSOE, 1997). A finales de los años noventa se intensificó la formación de las mujeres, sobre todo a raíz de la inminente aplicación del principio de paridad en las listas electorales en las elecciones municipales de 1999 y en las elecciones generales de 2000. La formación obedecía tanto al objetivo de evitar que el mayor reclutamiento de mujeres fuera cuestionado por ciertos sectores del partido debido a la menor educación política de las militantes, como de elevar la autoestima de las propias candidatas ${ }^{7}$.

\section{Acciones positivas en IU}

El PCE, a diferencia del PSOE, contaba ya en su organización durante la etapa de la clandestinidad con una sección integrada exclusivamente por mujeres. La Comisión de la Mujer del PCE fue durante muchos años una organización prácticamente autónoma dentro del partido, que trabajaba de forma muy estrecha con el Movimiento Democrático de Mujeres (MDM). Esta Comisión fue creada en los años cincuenta por un grupo de militantes comunistas con conciencia feminista, con la finalidad de "recordar" a sus camaradas varones que la ideología feminista debía ser

7. Isabel Martínez, ex Coordinadora de la Secretaría de Participación de la Mujer, entrevista personal, 18/11/04. 
parte de la lucha por la democracia. Estas mujeres defensoras de la doble militancia contaron con el rechazo de otras militantes feministas que renegaban de las relaciones con los partidos. Se crearon grupos de trabajo con mujeres trabajadoras, con amas de casa, con mujeres de presos políticos y con mujeres universitarias. En las charlas sobre feminismo organizadas entre 1977 y 1978 se estima que participó el 50 por ciento de las mujeres del partido (Astelarra, 2005: 130).

En IU, el Área de Mujer ha sido la sección tradicionalmente encargada de la discusión y redacción de las propuestas políticas, del debate de las iniciativas legislativas que afectan a temas de mujer, y de las relaciones con las organizaciones de mujeres. Entre los temas que el Área de Mujer tiene encomendados estatutariamente se incluye explícitamente la participación de la mujer en la organización ${ }^{8}$. Desde 1992 el Área de Mujer comparte sus responsabilidades con la Secretaría de Mujer. No ha habido, sin embargo, voluntad por parte de IU de crear organizaciones afines para que apoyen sus reivindicaciones, aunque la participación de militantes en las asociaciones de mujeres y la de las mujeres feministas en el partido haya sido un objetivo primordial (IU, 1992: 50).

El incremento de la militancia femenina había sido un objetivo estratégico del PCE y lo es de IU desde su constitución (IU, 1989: 33). Aunque el número absoluto de afiliados es mucho menor en IU que en el resto de los partidos analizados, el porcentaje de afiliación femenina es similar al de los partidos mayoritarios, algo menor que el del PP y ligeramente superior al del PSOE. A pesar de la insistencia de la Secretaría y del Área de Mujer del partido, las campañas de afiliación no han sido muy frecuentes debido a los escasos recursos económicos con los que ha contado la organización y no se ha implementado ninguna campaña específica para mujeres. Con todo, la militancia femenina se ha prácticamente triplicado en los últimos veinte años, pasando del 12,4 al 32 por ciento entre 1983 y 2004. Esta misma escasez de recursos ha limitado también las actividades formativas que la coalición ha podido ofrecer a sus miembros.

\section{Acciones positivas en el PP}

El PP cuenta desde la creación del partido en 1976 -Alianza Popular, entonces- con un departamento encargado de los temas de mujer. En los años ochenta se trataba de una vicesecretaría nacional de "promoción femenina" (de la "condición femenina" en años posteriores) y a partir de 1989, con la reestructuración del partido, se constituye en secretaría dentro del Área de Política Sectorial, primero, y de Política Social, después.

8. Estatutos Federales aprobados en la VIII Asamblea Federal (2004), Art. 12. En esta Asamblea pasa a denominarse "Área de Movimiento Feminista". 
Desde 1999 se denomina Secretaría de Igualdad de Oportunidades y Educación. No obstante, hasta finales de los años noventa, las actividades del partido en relación con la mujer, las relaciones con las organizaciones de mujeres, y la elaboración del correspondiente apartado del programa electoral estaban bajo la responsabilidad del Grupo Parlamentario en el Congreso de los Diputados. Dado que los grupos de trabajo del partido seguían el organigrama de las comisiones parlamentarias, eran los portavoces del PP que trabajaban en la Comisión de Derechos de la Mujer del Congreso los que mantenían relaciones con las asociaciones de mujeres y elaboraban las propuestas programáticas. Él/la portavoz de la Comisión era entonces el/la presidente/a de la Comisión de Trabajo correspondiente en el partido.

La inclusión de la Secretaría en el Área de Política Social es coherente con la tendencia manifiesta en los programas electorales: la mujer se ubica dentro del apartado de "bienestar social" pero no tiene espacio propio, los temas de género se mezclan con los dedicados a la familia, a los menores o a los discapacitados. El hecho de que estos temas sean tratados en la Secretaría como una cuestión de política social, de "igualdad de oportunidades", y al compartir espacio con la "educación", puede interpretarse como el resultado de un todavía débil protagonismo que las mujeres como grupo, y no así de forma individual, han tenido y tienen en el PP. Es decir, la Secretaría encargada de los temas de mujer se ubica en un segundo plano en la estructura orgánica del partido.

Las mujeres populares han contado con el apoyo de una organización de mujeres a la hora de introducir sus demandas en los programas del partido. Sin embargo, quien promovió su fundación no fueron las mujeres del partido sino Manuel Fraga, presidente de la Alianza Popular hasta 19909', quien en 1982 creó Mujeres Conservadoras (desde 1993, Mujeres para la Democracia, MD) como respuesta al asociacionismo de mujeres, mayormente vinculado a la izquierda. Aunque se considera ideológicamente afín al PP y simpatizante del mismo, MD se define como una organización independiente del partido ${ }^{10}$. Esta independencia se ve matizada por el hecho de que su sede se encuentra en el mismo edificio que alberga a diferentes Grupos de Estudio del PP y, en alguna ocasión, el partido se ha referido a la misma como la "organización del PP" (PP, 2002b: 49). Sus afiliadas participan, además, en la Comisión Nacional de Estudio de la Mujer del partido. Uno de los cauces más importantes de influencia es la doble militancia de muchas mujeres: un 30 por ciento de las afiliadas a MD pertenecen al partido y algunas de ellas ocupan cargos de responsabilidad. Por ejemplo, la vicepresidenta de la organización es, a su vez, la secretaria de Igualdad de Oportunidades en el partido.

9. En 1989 Alianza Popular se refunda y pasa a denominarse Partido Popular. Se produce entonces también un cambio en la presidencia, tomando el relevo José María Aznar.

10. Elena Bustillo, presidenta de la Federación Nacional de MD, entrevista personal, 7/4/05. 
En 1999, por primera vez, el partido celebró el 8 de marzo, Día de la Mujer, con una convención sobre "La mujer en la España de las oportunidades". Esta acción, sin embargo, no modificó la apreciación sobre la necesidad de implementar una política feminista en el partido. El entonces presidente nacional del PP, José $\mathrm{M}^{a}$ Aznar, manifestó durante el acto que el PP no hacía "feminismo de salón" sino de "hechos, realidades y oportunidades". Precisó también que este acto debía tomarse como otro más del partido, como algo sin carácter excepcional, y alertó a las mujeres que "no se especializaran en sus reivindicaciones", mostrando de forma más o menos explícita su rechazo al feminismo y a la creación de un lobby de mujeres en la organización ${ }^{11}$. Por ello, ni el partido ni la Secretaría de Igualdad de Oportunidades han considerado necesaria una formación política específica para sus afiliadas y candidatas.

Las campañas de afiliación del PP no han sido habituales, a excepción de los primeros años de la década de los ochenta. En lo que a afiliación femenina se refiere, el PP es el partido que más mujeres afiliadas tiene sin haber emprendido nunca campañas de afiliación específicas para mujeres. Actualmente, cuenta con un 33,6 por ciento de afiliadas en sus filas. Son varias las razones que pueden explicar una mayor militancia femenina en los partidos de derecha. En primer lugar, las mujeres de estos partidos suelen proceder en mayores proporciones de clases acomodadas, lo que les permitiría liberarse con más facilidad del trabajo doméstico y tener un nivel cultural más elevado (García Escribano y Frutos, 1999: 316). Segundo, es importante recordar que los partidos de izquierda se han desarrollado en estrecha colaboración con los sindicatos y el mundo del trabajo, ámbito en el que la mujer se ha incorporado mucho más tarde que el hombre y donde, todavía hoy en España, la tasa de actividad de la mujer es sólo del 56 frente al 80 por ciento de los hombres. Por otra parte, muchos partidos de derecha han mantenido estrechas relaciones con la Iglesia, institución a la que las mujeres estuvieron tradicionalmente muy vinculadas y en la que muchas de ellas iniciaron sus actividades públicas (Uriarte, 1995: 126).

La incorporación paulatina de la mujer al mercado laboral y la erosión gradual de la influencia social de la Iglesia habrían ido debilitando la "ventaja comparativa" que los partidos de derecha tenían sobre los partidos de izquierda, factores que contribuirían a explicar el similar porcentaje de afiliación femenina en la actualidad de los tres partidos de ámbito estatal. El PP supera en la actualidad al PSOE por dos puntos porcentuales y a IU por uno. No obstante, de 1980 a 2004 es el partido cuya proporción de mujeres menos ha aumentado, con un incremento inferior a los seis puntos porcentuales, una tasa de crecimiento tres veces por debajo de la de los partidos de izquierda, como apre-

11. El País, 7 de marzo de 1999. 
ciamos en el Gráfico 1. Para las mujeres socialistas está claro que el aumento de afiliadas se debe, en buena medida, al impulso proporcionado por la cuota ${ }^{12}$.

\section{Gráfico 1}

\section{Ratio mujeres afiliadas/Total afiliación (M/T)}

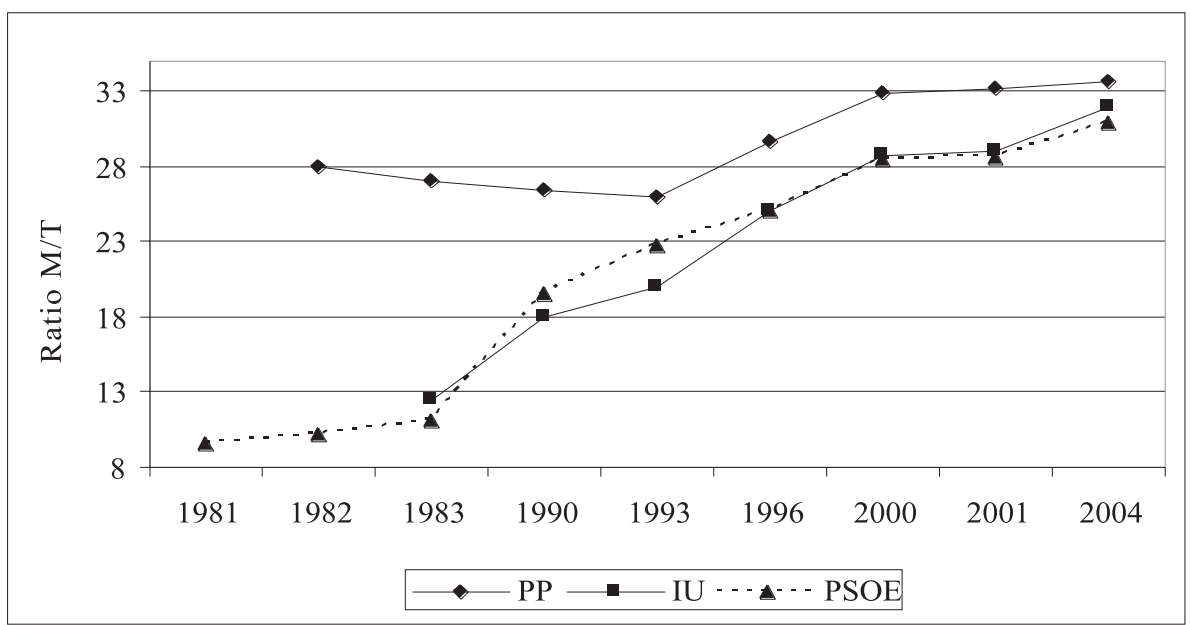

Fuente: Elaboración propia. Datos del PSOE: PSOE (2001a) y datos facilitados por la Secretaría de Organización; Datos de IU: Ramiro (2004) e Instituto de la Mujer (1999); Datos del PP: Sánchez Férriz (2000: 232), PP (2002b, 2004b).

\section{Estrategias de discriminación positiva}

\section{Discriminación positiva en el PSOE}

Aunque el discurso oficial del partido apoyara el incremento del peso orgánico y público de las mujeres, los avances materiales en los primeros años de la democracia fueron muy marginales. Sirvan como ilustración estos ejemplos: en 1979 el número de mujeres candidatas en las listas de las elecciones legislativas fue ligeramente inferior al de 1977 y el porcentaje de candidatas en la primera mitad de la lista se redujo en un 50 por ciento. En 1982 las listas electorales al Congreso de los Diputados contenían un pírrico 8,3 por ciento de mujeres. Por otro lado, en 1981, sólo tres mujeres figuraban entre los miembros de la Comisión Ejecutiva Federal (PSOE, 1988c). Ante esta lenta evolución, la Secretaría de Participación de la Mujer publicó el Documento sobre indices de representación de las

12. Mariví Monteserín, ex coordinadora de la Secretaría de Movimientos Sociales, entrevista personal, $30 / 11 / 04$. 
mujeres socialistas (PSOE, 1985) con el objetivo de constatar ante la militancia y la dirección del partido que la representación de las mujeres en los órganos de decisión y en los cargos públicos electos no alcanzaba ni siquiera el porcentaje global de afiliación femenina.

Por otro lado, la Internacional Socialista de Mujeres (ISM) ha sido la gran impulsora de las cuotas entre los partidos miembros de la Internacional Socialista (IS) ${ }^{13}$. En 1986, en la Conferencia de Lima, la ISM declaró el "Decenio Socialista de la Mujer" y pidió a los partidos afiliados que facilitaran la participación de mujeres en la vida política, logrando que estuvieran representadas en todos los órganos de los partidos y en las candidaturas electorales (ISM, 1986). Siguiendo pues las recomendaciones de acción positiva impulsadas por la ISM, la Secretaría de Participación de la Mujer realizó una encuesta al conjunto de la afiliación acerca de la necesidad de que el partido tomara medidas para que las mujeres participaran más en puestos de responsabilidad y sobre la posible inclusión en los estatutos del PSOE de ciertas disposiciones que reservasen a las mujeres una determinada proporción de puestos orgánicos y electorales, consiguiendo en estas dos preguntas, respectivamente, un 88 y un 67 por ciento de respuestas afirmativas. Además, la Secretaría desarrolló una intensa "campaña de lobby" en el interior del partido para asegurarse los votos necesarios en el XXXI Congreso (1988) a favor de la cuota. Con estos precedentes, el PSOE aprobaba una presencia mínima de mujeres del 25 por ciento en las listas internas o de representación popular ${ }^{14}$.

Dado que en la práctica se estaba produciendo un nulo avance en la representación de la mujer al aplicarse el 25 por ciento en el conjunto de una lista y no en los puestos con posibilidades reales para ser elegidas, en 1994 se estableció que, cuando la afiliación de mujeres fuera mayor del 25 por ciento, la cuota estaría cinco puntos por encima del porcentaje de afiliación en el ámbito correspondiente. Esta cuota sería aplicable a todos los procesos electorales, tanto para el conjunto de cada lista como para los

13. Las socialistas españolas han ocupado varias vicepresidencias en la ISM y una Presidencia, M $^{\text {a }}$ Dolors Renau (1999-2003).

14. Enmiendas a los Estatutos Federales de 1988, Art. 8.k. La propuesta en el XXXI Congreso generó mucha más controversia de lo que suele ser habitual en la discusión de una propuesta, y Carmen Romero, la esposa de Felipe González, hizo lobby a favor de la cuota (Craig, 1995: 18). El Centro de Investigaciones Sociológicas (CIS) realizó en febrero de 1988 un estudio sobre la discriminación de la mujer en la esfera laboral, educativa y política (CIS estudio núm. 1728). El 61 por ciento de los y las encuestados/as se mostraban de acuerdo en que la cuota contribuye a disminuir la discriminación de la mujer y apoyaban su introducción en el PSOE (Cambio 16, extra "Españolas 88: cada vez mejores", 18 de abril de 1988). Según una encuesta del mismo centro diseñada en 2005, el porcentaje de entrevistados/as que se mostraban de acuerdo con una presencia mayor de las mujeres en las listas de los partidos se había elevado al 67 por ciento y el 63 por ciento de los mismos apoyarían la introducción de medidas que garantizasen la paridad en el Congreso de los Diputados (CIS, estudio núm. 2588). 
puestos iniciales con posibilidades razonables de resultar electos ${ }^{15}$. En este Congreso, la democracia paritaria se declaraba ya como un objetivo inminente. El propio Secretario General, Felipe González, declaraba:

El 33 por ciento de las mujeres las he propuesto para que estén representadas en esta Comisión Ejecutiva. Y os voy a decir algo más, en el próximo Congreso estaremos en condiciones, todos, de conseguir ya los límites de la democracia paritaria. Os lo ruego, haced este esfuerzo en los Congresos Provinciales y en los Congresos Locales, haced este esfuerzo en toda la organización, hacedlo en las listas. No será gratuito, pues eso formará parte, con anticipación, de uno de los grandes cambios que se van a producir en nuestra sociedad (PSOE, 1994a: 246).

No obstante, el paso más decisivo hacia el avance de la discriminación positiva se produce en el XXXIV Congreso (1997) donde se asume la "democracia paritaria" como principio estatutario y se reconoce la contribución del feminismo a la consolidación de la democracia. Se instauró un sistema de cuotas en virtud del cual ningún sexo deberá tener menos del 40 ni más del 60 por ciento de representación en cualquier órgano del partido, así como en todos los cargos y responsabilidades que el PSOE ocupe. Para asegurar una representación igualitaria, se instaura la alternancia de hombres y mujeres tanto en la totalidad de la lista como en el conjunto de puestos que se esperan obtener ${ }^{16}$. La secretaria de Participación de la Mujer y la ex directora del Instituto de la Mujer se incorporaron a la Comisión Federal de Listas ${ }^{17}$. Este hecho obedecía al incumplimiento de la cuota que se había producido en las elecciones autonómicas gallegas de 1997 y en las elecciones vascas de 1998, cuando la paridad ya había sido asumida por el partido. En las elecciones autonómicas y municipales de 1999 y en las elecciones generales de 2000 se invalidaron algunas listas que no respetaban la cuota y, en posteriores convocatorias electorales, algunas listas fueron incluso modificadas para hacer cumplir la paridad en los puestos iniciales ${ }^{18}$.

Por último, el I Plan de Igualdad (PSOE, 2002) aprobó que la paridad también se aplicaría a las elecciones indirectas (por ejemplo, en las Dipu-

15. Estatutos Federales aprobados en 1994, Art. 9.k

16. Estatutos Federales aprobados en 1997, Art. 9.k.

17. Después de la victoria electoral del PSOE en 1982, un grupo de mujeres socialistas comenzaron a presionar a distintas figuras del partido a fin de que se cumpliera la promesa electoral de crear una comisión para la igualdad (Valiente, 1994). En 1983 se creó el Instituto de la Mujer como organismo encargado de promover y fomentar las condiciones para posibilitar la igualdad social de ambos sexos y la participación de la mujer en la vida política, cultural, económica y social. Se encargó su diseño y posterior dirección a Carlota Bustelo, la feminista más reconocida del partido, diputada en la legislatura constituyente y que en 1979 había renunciado a presentarse a las elecciones legislativas, a pesar de ocupar un puesto seguro en la lista por Madrid, en protesta por el escaso número de mujeres candidatas.

18. Isabel Martínez, ex coordinadora de la Secretaría de Participación de la Mujer, entrevista personal, $18 / 11 / 04$. 
taciones Provinciales) y el Comité Federal extendió este principio en noviembre de 2004 a la composición de los órganos de dirección de los grupos parlamentarios de las distintas cámaras legislativas (estatal, autonómico y europeo).

\section{Discriminación positiva en IU}

La introducción de la cuota en IU vino de la mano del PCE que en octubre de 1987 había garantizado una representación del 25 por ciento en sus cargos internos para las mujeres. IU asumiría el compromiso en su I Asamblea Federal (IU, 1989: 33). En 1990, el porcentaje fue en la práctica elevado al 35 por ciento cuando se estipuló que, tanto en los órganos de dirección como en las candidaturas electorales, ninguno de los sexos debía ocupar más del 65 por ciento de los puestos.

En 1997 se produce un nuevo avance al aprobarse que ningún sexo podrá superar el 60 por ciento en los diferentes tramos de la lista, tanto en las listas internas como en las candidaturas electorales. En 2004 se introdujo la disposición en cremallera de las listas con alternancia entre ambos sexos de forma paritaria ${ }^{19}$.

\section{Discriminación positiva en el PP}

En marzo de 1999, el presidente nacional del PP revelaba que había ordenado al Comité Electoral de su partido que no aceptase aquellas propuestas de listas para los comicios municipales y autonómicos de 1999 que no incluyeran alguna mujer en puestos de salida y afirmaba que "las proporciones conocidas" para la composición de las citadas listas "donde predominan los hombres sobre las mujeres se van a invertir a partir de ahora". Asimismo, en su III Congreso (marzo de 2001), la entonces presidenta de Mujeres para la Democracia (MD), Isabel Tocino, reclamó una mayor presencia de las afiliadas de MD en las listas municipales y autonómicas (Baón, 2001). No obstante, estas afirmaciones no modificaron un ápice la posición del partido sobre la discriminación positiva: "Aquí se está porque se vale, no por cuota sino por nota y porque se tiene la confianza del partido y de la sociedad" (PP, 2002a: 148).

El rechazo a las cuotas se vio igualmente reflejado en su actividad gubernamental en el período 1996-2004. El PP impidió la introducción en los sistemas electorales estatal y autonómico de porcentajes mínimos en las listas de candidatos para cualquiera de los dos sexos. Por un lado, los parlamentos de Castilla-La Mancha y Baleares introdujeron en junio de 2002 en sus respectivas leyes electorales la paridad en las listas (50 por

19. Estatutos Federales aprobados en 2004, Art. 14 
ciento de candidatos de cada uno de los dos sexos). El gobierno del PP interpuso, en septiembre de ese mismo año, sendos recursos de inconstitucionalidad que todavía no han sido resueltos. Por otro lado, el 8 de abril de 2002 se presentaron en el Congreso de los Diputados tres Proposiciones de Ley del PSOE, de IU y de Iniciativa per Catalunya -Els Verds para reformar la Ley Orgánica del Régimen Electoral General (LOREG) con el objetivo de equilibrar la presencia de hombres y mujeres en las listas electorales ${ }^{20}$. Las iniciativas contaron con el apoyo de todos los partidos de la oposición y con el rechazo del gobierno del PP.

Por otro lado, el PP trasladó su posición contraria a la discriminación positiva a los Planes de Igualdad de Oportunidades para la Mujer (PIOM) elaborados por el Instituto de la Mujer ${ }^{21}$. Así, mientras que en el II PIOM la promoción del pleno acceso de las mujeres a puestos de responsabilidad, incluyendo la actividad política, se estableció como uno de los tres campos de alta prioridad de actuación, desaparecieron del III PIOM todas las referencias y las acciones destinadas a impulsar la igualdad en la representación y en la participación política, así como el trabajo conjunto con los partidos políticos para conseguir el equilibrio en la representación. Este objetivo quedó reducido a las empresas y a los agentes sociales, y el IV PIOM sólo rescató la promoción de la presencia equilibrada de los dos sexos en las administraciones públicas.

En suma, el PP considera, por un lado, que una medida de este tipo resulta inconstitucional porque atenta contra el propio principio de la igualdad y contra el principio de libre asociación, al impedir la concurrencia electoral a aquellas asociaciones legalmente constituidas pero que no apliquen la cuota. Por otro lado, sostiene que el criterio de elección debe estar basado en las capacidades personales, en el mérito individual, porque, de no ser así, se estaría produciendo una discriminación negativa hacia los hombres ${ }^{22}$. Se manifiesta también que la relación de confianza entre los representantes y los ciudadanos es "independiente de la edad, sexo, procedencia geográfica, raza o cualquier otra condición" (PP, 2004c: 10).

20. En años anteriores estos mismos grupos parlamentarios habían presentado Proposiciones no de Ley que instaban al incremento de la presencia de las mujeres en los cargos de responsabilidad y decisión política. La Proposición no de Ley del Grupo Parlamentario Federal de Izquierda Unida-Iniciativa per Catalunya, presentada en 1996, reclamaba la participación paritaria de hombres y mujeres en los cargos públicos (Boletín Oficial de las Cortes Generales D-24, 14 de junio 1996) y caducó sin llegar a tramitarse. Igual suerte corrió la Proposición no de Ley del Grupo Parlamentario Socialista sobre la aprobación de un plan de acción para la participación de las mujeres en la toma de decisiones en todos los niveles presentada en 1999 (Boletín Oficial de las Cortes Generales D-467, 20 de julio 1999).

21. El Instituto de la Mujer ha desarrollado hasta la fecha cuatro Planes para la Igualdad de Oportunidades: I PIOM (1988-1990), II PIOM (1993-1995), III PIOM (1997-2000) y IV PIOM (2003-2006).

22. Juan Carlos Vera, secretario de Organización del PP, entrevista personal, 31/1/05. 
Aunque la mayoría de las mujeres del PP comparten la opinión de que la progresiva incorporación de la mujer en la vida política contribuye a mejorar la democracia, y que la equiparación política entre hombres y mujeres ahonda en su consolidación, se manifiestan escépticas, como sus compañeros de partido, en cuanto al uso de las cuotas, bien por la discriminación que supone para los hombres del partido, bien por la discriminación que implica para las propias mujeres el hecho de ser consideradas una "mujer-cuota" 23 . También enfatizan el incremento gradual en el número de mujeres populares que han ido accediendo a puestos de responsabilidad política:

El Partido Popular, cree en los principios de capacidad y de mérito, tanto de hombres como de mujeres, y creemos en la igualdad de oportunidades (...). Las mujeres del Partido Popular no queremos estar en unas listas electorales por cuotas ni por cremalleras, porque nos parece humillante, porque nos parece un atentado a nuestra dignidad y porque las mujeres diputadas del Partido Popular que hoy se sientan en estos escaños creemos -estamos firmemente convencidas de ello- que estamos aquí porque en su día nuestro partido pensó que éramos las mejores" 24 (María Mercedes Roldós, diputada del PP en la VII Legislatura).

¿Por qué las mujeres tenemos que tener techo? Hay listas electorales donde el número 1 y el 2 de las listas son mujeres. ¿Por qué hay que alternar hombres y mujeres? Tenemos que dar facilidades, no poner límites. La paridad en el Gobierno nos ha demostrado a lo que conduce: en los altos cargos, ¿cuántas Secretarias de Estado o Directoras Generales hay? ¿Hablamos de política de cara a la galería o de políticas reales? (...). El PP ha incrementado la participación de las mujeres de forma muy importante sin haber necesitado una política de cuotas (Sandra Moneo, secretaria de Igualdad de Oportunidades y Educación del PP, entrevista personal, 25/4/05).

El argumento del mérito es el que ha recibido más críticas por parte de militantes de izquierda al considerarlo falaz por basarse en la premisa de la existencia real de una igualdad de oportunidades que en la práctica, según estas mujeres, se demuestra falsa. Algunas de éstas han afirmado que detrás del argumento de la "calidad frente a la cantidad" se esconde una "misoginia camuflada de excelencia" que presupone que los hombres que obtienen representación son "los mejores" mientras que este

23. Amalia Gómez, ex secretaria general de Asuntos Sociales, hizo referencia a la cuota como "cuota wonderbra", y Teófila Martínez, ex presidenta del PP en Andalucía, manifestó que un tratamiento de este tipo equivale a ver a las mujeres como "animales en vías de extinción, susceptibles de ser protegidas". Por su parte, Isabel Tocino, diputada del PP en el Congreso de la III a la VII Legislatura y ex ministra de Medio Ambiente, también manifestó: "Sigo considerando que el que nos admitan como mujeres-cuota no deja de ser una cierta discriminación (...). Vamos en un ascenso tremendo. Esto yo creo que está bien y tendremos que luchar por ello, pero desde mi punto de vista no como una tasa del tanto por ciento" (El País, 31 de agosto de 1998).

24. Diario de Sesiones del Congreso de los Diputados, Núm. 45, 2 de noviembre de 2004. 
supuesto se convierte en "sospecha" cuando es una mujer quien obtiene el cargo (Camps, 1998; Renau, 1998).

No obstante, en el XV Congreso (2004), se presentó una enmienda a los Estatutos para incorporar un mayor compromiso con el equilibrio de género en la representación política. Esta enmienda fue finalmente recogida en el Preámbulo de los Estatutos a modo de recomendación, no teniendo empero reflejo en el articulado de los estatutos: "Constatamos el avance que se ha producido durante estos últimos años, pero consideramos que hay que seguir progresando hacia la igualdad plena entre hombres y mujeres en los órganos de dirección del partido, así como en su representación institucional" 25 . Según el promotor de la iniciativa, el diputado de la Asamblea de Madrid, Juan Soler, esta enmienda pretendía constatar que "en la práctica, el PP sitúa en puestos de responsabilidad a más mujeres que ningún otro partido, pero la gente no lo percibe, o incluso lo ve como machista" 26 .

\section{Factores internos y externos}

En primer lugar, queremos averiguar si la competición electoral ha podido jugar un papel relevante en el aumento de la representación de las mujeres. Diferentes estudios coinciden en apuntar que la captación del voto femenino empujaría a los partidos a incorporar esta reivindicación como estrategia de atracción de más de la mitad del electorado (Sánchez Férriz, 2000: 221; Norris, 1993: 315). Si observamos la evolución del voto por géneros o "distancia ideológica de género", se constata que las mujeres, en general, han venido votando más a la derecha que los hombres, si bien las diferencias se han reducido considerablemente (véase el Gráfico 2) ${ }^{27}$.

25. Preámbulo de los Estatutos Nacionales aprobados en octubre de 2004.

26. El País, 24 de septiembre de 2004.

De hecho, bajo el Gobierno del PP (1996-2004), España ha tenido la primera presidenta del Congreso, presidenta del Senado, comisaria de la Unión Europea o la primera presidenta de una Comunidad Autónoma (Madrid). No obstante, el PP elabora sistemáticamente unas listas electorales con menor presencia femenina que los partidos de izquierda. Por otro lado, aunque es el partido que más listas presenta con mujeres en la cabeza de la candidatura, también es la formación con un mayor porcentaje de listas que no incorporan a ninguna mujer (Verge, 2005). Es decir, el PP ha ubicado tradicionalmente a sus candidatas en puestos de alta visibilidad pública pero, en general, su representación es mucho menor que la alcanzada por las mujeres del PSOE y de IU.

27. El indicador se calcula: (\% de mujeres con recuerdo de voto a la izquierda - $\%$ de mujeres con recuerdo de voto a la derecha) - (\% de hombres con recuerdo de voto a la izquierda - \% de hombres con recuerdo de voto a la derecha). Si es positivo indica que las mujeres votan a la izquierda más que los hombres y, si es negativo, que las mujeres votan más a la derecha (García Escribano y Frutos, 1999). 


\section{Gráfico 2}

\section{Distancia ideológica de género}

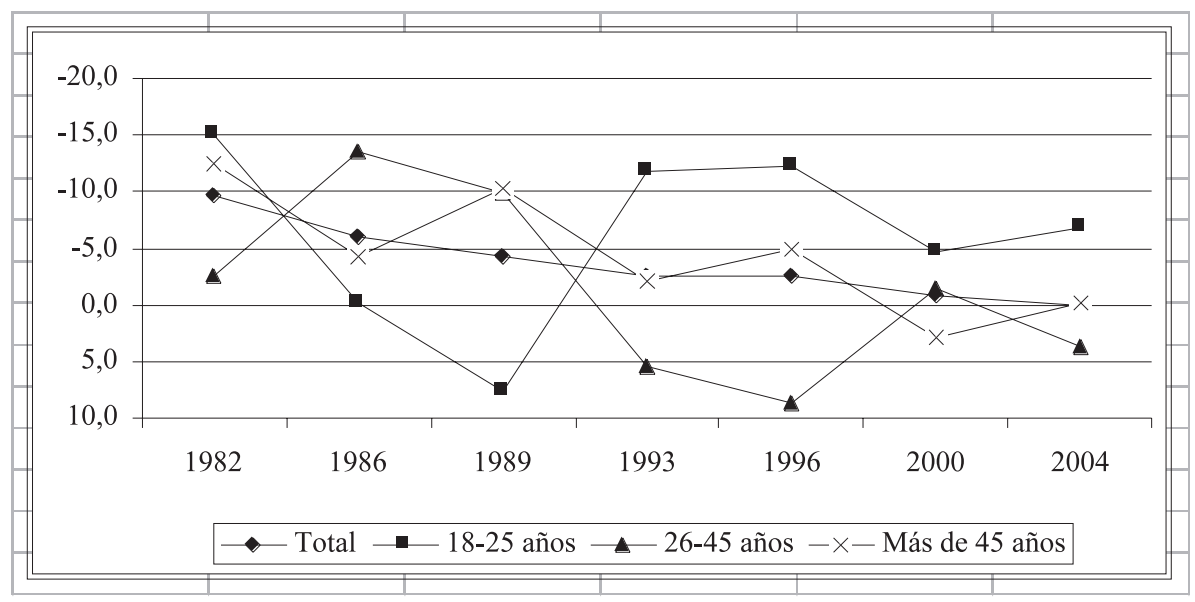

Fuente: Elaboración propia a partir de los estudios postelectorales del CIS (1982-2004).

Las mujeres jóvenes votaron más a la derecha hasta 1989 -año incluido- y, posteriormente, se repite este voto conservador en 1996. En cuanto a las adultas, éstas han venido votando más a la derecha hasta 1996 (García Escribano y Frutos, 1999: 327). En el 2000, el 60 por ciento de las mujeres y el 59 por ciento de los hombres votaron a la derecha. Por franjas de edad, siguiendo la "distancia ideológica de género", las mujeres jóvenes votaron más a la derecha en comparación con los hombres de su edad que aquéllas de las generaciones mayores. No obstante, el 44 por ciento de las mujeres jóvenes votó a la izquierda y sólo lo hicieron el 38 por ciento de las mujeres mayores. En 2004 se produce la misma tendencia, las mujeres jóvenes votaron más a la derecha en comparación con los hombres de su edad y las mujeres mayores votaron levemente más a la izquierda. Ahora bien, el 75 por ciento de las mujeres jóvenes votó a la izquierda, mientras que sólo lo hizo el 55 por ciento de las mayores.

Podemos ver en el Gráfico 2 que la "distancia ideológica de género" se ha ido evaporando de forma gradual hasta su práctica extinción. Esta diferencia ha pasado de -9,1 en 1982 a 0,1 en 2004, es decir, el indicador no sólo ha dejado de ser negativo sino que, en 2004, las mujeres votaron ligeramente en mayor proporción a los partidos de izquierda que a los de derecha. Paradójicamente, son las mujeres mayores quienes más han reducido la distancia, mientras que las jóvenes siguen optando en mayor medida que los hombres de su misma generación por los partidos de derecha. 
Gráfico 3

Votantes de los tres partidos por género

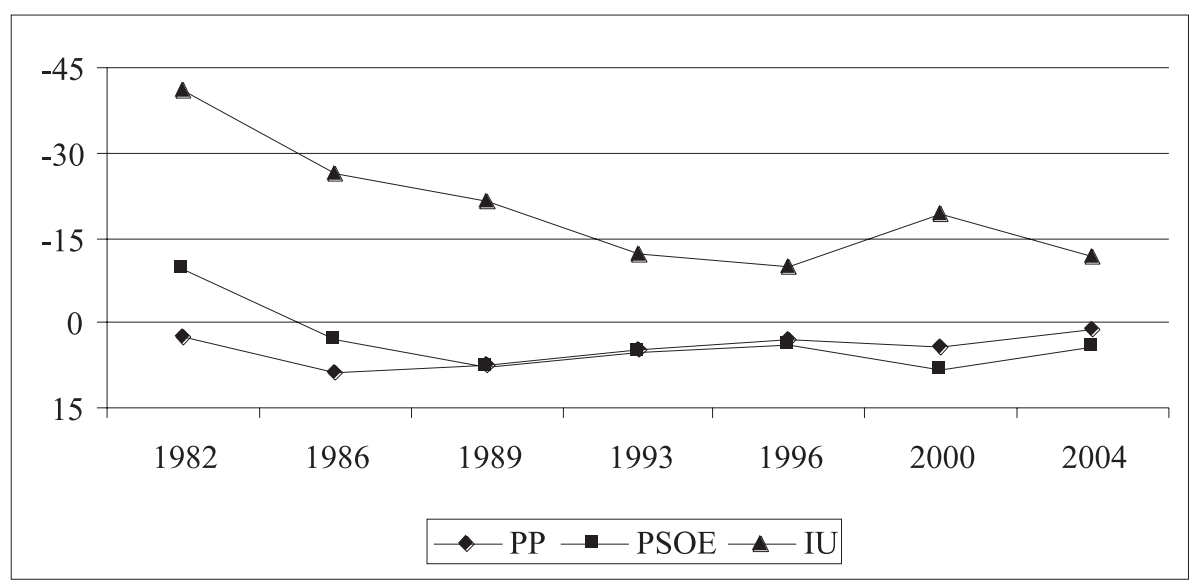

Fuente: Elaboración propia a partir de los estudios postelectorales del CIS (1982-2004).

Analizando solamente el electorado de los tres partidos, se destacan varias tendencias (véase el Gráfico 3). Mientras que los electorados del PP y del PSOE han sido en mayor proporción femeninos durante todo el período estudiado, el electorado de IU es netamente masculino. El electorado popular se ha homogeneizado progresivamente hasta equilibrarse en su composición y, entre 1982 y 2004, las mujeres han aumentado un 400 por ciento entre los votantes de IU, a pesar de que la diferencia que les separa de los hombres es todavía notable. Por otro lado, mientras que hasta 1986 el PP tenía más mujeres entre sus votantes que el PSOE, a partir de 1989 se invierte la tendencia y es el PSOE el que aventaja al PP en este porcentaje. De este modo, los partidos de izquierdas tenían en la década de los ochenta y principios de los noventa fuertes incentivos para implementar aquellas políticas que contribuyesen a cambiar la dirección del voto conservador de una parte importante de las mujeres, especialmente IU cuyos votantes tenían un perfil predominantemente masculino, pero también el PSOE si quería seguir sumando apoyos y no perder la mayoría parlamentaria. De hecho, las Secretarías de Mujer de estos partidos no dudaban en utilizar este argumento para convencer a sus compañeros de partido:

[Las] medidas de acción positiva de los distintos partidos europeos han tenido como repercusión un aumento de la afiliación femenina y, por tanto, mayor participación, tanto cuantitativa como cualitativa, que se ha proyectado en la sociedad obteniendo no sólo una cantidad de votos, sino un claro apoyo electoral (PSOE, 1985).

Se puede observar que la introducción de la cuota y la elevación sucesiva del porcentaje reservado a las mujeres discurren en paralelo en los 
dos partidos de izquierda. No deja de ser llamativo que la paridad fuera aprobada por el PSOE tras perder las elecciones generales de 1996: si quería ser el partido que defendía mejor los intereses de las mujeres, tenía que implementar medidas efectivas y hacerlas respetar. El mismo razonamiento puede aplicarse a IU: los resultados electorales de 1996 no cumplieron las expectativas de la dirección que vio cómo fracasaba su objetivo de acercarse o incluso adelantar al PSOE.

El PSOE, además, atravesaba una grave crisis interna y tenía que hacer frente a una deteriorada imagen pública (escándalos de corrupción, financiación irregular del partido, caso GAL, etc.). Estos hechos pudieron contribuir a la adopción de medidas que mejorasen la credibilidad del partido como uno de los valores que se querían enfatizar frente a su máximo rival, el PP. Por otra parte, la introducción de la paridad en el XXXIV Congreso (1997), el primer congreso del partido en la oposición desde 1984, se produce en un contexto de claras luchas faccionales en el que Felipe González, quien fuera Secretario General del partido en los últimos 23 años, renunció a presentarse a la reelección. Joaquín Almunia recibió el apoyo de más del 70 por ciento de los delegados asistentes como nuevo líder del partido, pero necesitaba renovar la Ejecutiva del partido para poder ejercer un liderazgo más nítido.

Algunos autores han argumentado que, para controlar un proceso de cambios, las coaliciones dominantes recurren a procedimientos de cooptación cuya justificación puede ser bien el cambio generacional o bien la discriminación positiva (Panebianco, 1990: 462). En el caso del PSOE, en 1997, 18 de los 33 miembros de la nueva Comisión Ejecutiva Federal se incorporaron por primera vez a este órgano, de entre los cuales dos pertenecían a las Juventudes Socialistas (un hombre y una mujer) y otros diez eran mujeres. Es decir, el 61 por ciento de los nuevos miembros eran mujeres. Desde esta perspectiva, cabría dar cierta validez a la hipótesis de la utilización de la discriminación positiva como estrategia de cooptación.

No obstante, desde la introducción de la cuota del 25 por ciento en 1988, la dirección había aplicado una pequeña "trampa" para incorporar a más mujeres sin despertar rechazo en algún sector del partido: incrementar el número de miembros de la Ejecutiva. En 1984 integraban este órgano 17 miembros y en 1988 pasan a ser 23, elevándose entonces de 3 a 6 las mujeres presentes en este órgano. En 1990 el número de integrantes de la CEF se eleva a 33 pero la presencia femenina permanece estable (7). En el XXXIII Congreso (1994) se sumaron tres nuevos miembros y el número de mujeres se elevó a 11 (PSOE, 2001a). Esta tendencia se interrumpe a partir de 1997 cuando el número de componentes de la Comisión Ejecutiva Federal se reduce progresivamente mientras que la representación femenina experimenta un ascenso en cada nuevo congreso. Además, a partir de 1997, el cumplimiento de la cuota ha sido efectivo en todos los procesos 
electorales ${ }^{28}$. Asimismo, fue precisamente Almunia quien propuso por primera vez la reforma de la LOREG para incorporar las listas paritarias. Es decir, el apoyo del nuevo liderazgo a la paridad se mantuvo sin ambigüedades en años posteriores. Este objetivo ya había sido fijado en 1994 y su incumplimiento habría restado credibilidad al compromiso público del partido con la igualdad en la representación política.

Por su parte, el PP ha rechazado sistemáticamente el uso de la cuota, pero tanto en su estructura interna como en sus cargos públicos ha sido considerable el incremento de mujeres. En 1993 el PP prácticamente dobló su representación femenina en el Congreso y, a pesar de que el porcentaje se mantuvo estable en las siguientes elecciones generales, a partir de 2000 se produce un nuevo aumento. Este incremento está muy ligado al experimentado por su principal competidor en la arena política, el PSOE. No hay que olvidar que en las elecciones de 1993, cuando las encuestas preelectorales daban una ligera ventaja al PP sobre el PSOE, todos los esfuerzos del partido se dirigían a captar a un sector del electorado socialista. Además, el PP había perdido su ventaja comparativa en cuanto a la atracción del voto femenino.

En definitiva, tanto la competencia electoral como la permanencia en la oposición han actuado como importantes estímulos externos para los partidos y han resultado ser grandes aliados de la demanda de una mayor representación femenina. Ahora bien, en la implementación de estas estrategias han resultado también fundamentales ciertos factores internos. Tanto en el giro discursivo del partido como en la aceptación de la cuota jugó un papel destacado la presión ejercida por las Secretarías de Mujer, confirmando que la existencia de una masa crítica de mujeres que apoyen estas reivindicaciones y su poder orgánico en el partido es determinante en estos procesos.

Las estrategias discursivas puestas en marcha por las mujeres de los partidos de izquierda resultaron fundamentales como paso inicial para la incorporación de las mujeres a los puestos de responsabilidad política. Durante los primeros años de la década de los ochenta, tras la incorporación de las primeras mujeres a los órganos de dirección del PSOE, del PCE y de IU, los temas "de mujer" fueron redefinidos como demandas por la igualdad entre géneros. A pesar de que en esos años la agenda política de la igualdad de género estaba dominada por propuestas relativas al mercado laboral o a las políticas sociales, al romper con la concepción de que los temas de mujeres eran cuestiones sectoriales, se preparó el terreno para el giro discursivo que se produciría a finales de esa misma década. Con importantes consideraciones estratégicas, la representación de las mujeres se transformó en una demanda que pretendía mejorar la calidad de la

28. En las elecciones generales de 1996, 2000 y 2004 el porcentaje de mujeres en las listas socialistas fue del 38,46 y 44 por ciento, respectivamente. 
democracia. Se convirtió, entonces, en un derecho de ciudadanía: a las mujeres, siendo la mitad de la población, les correspondía de forma legítima una participación mucho mayor en los puestos de responsabilidad de la que gozaban hasta la fecha. Presentando la infrarrepresentación de las mujeres como una contradicción con los principios democráticos, resultaba difícil exponer argumentos en contra de su demanda. De esta forma, las Secretarías de Mujer consiguieron convencer a sus compañeros de partido de la necesidad de introducir cuotas tanto en la configuración de los órganos internos como en las listas electorales.

Las cuotas iniciales dotaron a las mujeres de un valioso poder orgánico que les garantizaba una mayor capacidad de presión para incrementar la presencia femenina en los cargos orgánicos y en los públicos, y para la ampliación progresiva de la cuota. En la Tabla 2 se presenta la evolución de la presencia femenina en los máximos órganos federales de los partidos. En el mismo Congreso en que el PSOE aprobó la cuota del 25 por ciento (1988), la representación femenina pasó del 18 al 26 por ciento en la Comisión Ejecutiva Federal (CEF). El nuevo impulso a la cuota en 1994 vuelve a producir un aumento notable de las mujeres (31 por ciento) y, a partir de 1997, tras la aprobación de la paridad, el porcentaje de mujeres supera siempre el 40 por ciento. En 2004 se produce prácticamente un equilibrio de géneros, con un 48 por ciento de representación femenina en la CEF y un 54 por ciento en la Comisión Permanente.

Tabla 2

Evolución de la participación femenina en los máximos órganos ejecutivos (\%)

\begin{tabular}{lcccccccc}
\hline & $\mathbf{1 9 8 1}$ & $\mathbf{1 9 8 4}$ & $\mathbf{1 9 8 7}$ & $\mathbf{1 9 9 0}$ & $\mathbf{1 9 9 4}$ & $\mathbf{1 9 9 7}$ & $\mathbf{2 0 0 0}$ & $\mathbf{2 0 0 4}$ \\
\hline$P P(C E N)$ & 4 & 8 & 7 & 18 & $18(1993)$ & $12(1996)$ & $22(1999)$ & 28 \\
PSOE (CEF) & 12 & 18 & $26(1988)$ & 21 & 31 & 42 & 40 & 48 \\
$I U(P E F)$ & - & - & N.d. & $25(1992)$ & 26 & 29 & 21 & 25 \\
\hline
\end{tabular}

Fuente: PP: Datos de 1981 a 1999 extraídos de Ruiz Jiménez (2002) y de 2004 datos facilitados por el PP; PSOE: PSOE (1985, 1998 y 2001a). Datos de 2004 en http:/ / www.psoe.es; IU: datos facilitados por el Área de Mujer.

N.d.: no disponible

En IU las mujeres constituyen el 25 por ciento de la Presidencia Ejecutiva Federal (PEF) frente al 29 por ciento, que representaban en 1997. En la actual Comisión Permanente encontramos un 32 por ciento de mujeres. A pesar del impacto positivo que ha tenido la introducción de la cuota, se observa que en los órganos federales de IU existe todavía un "techo de cristal" y que se ha incumplido la disposición estatutaria relativa a la paridad. 
El rechazo del PP a la discriminación positiva ha supuesto un freno a una representación política más equilibrada en su seno, aunque las mujeres populares han conseguido también aumentar su participación de forma progresiva. El porcentaje de mujeres en el Comité Ejecutivo Nacional (CEN) en los años ochenta no fue nunca superior al 8 por ciento. En los años noventa se produce un incremento gradual que culmina en 2004 con un 28 por ciento de mujeres en ese órgano. No obstante, en el órgano ejecutivo más operativo, el Comité de Dirección, su presencia sigue siendo minoritaria ( 9 por ciento).

Las Secretarías de Mujer pudieron hacer valer en esos años el apoyo que, tanto distintas organizaciones y conferencias internacionales como organizaciones afines al partido y organizaciones feministas de ámbito nacional, prestaban al objetivo de la igualdad en la representación avalando las medidas de discriminación positiva. En 1995 se celebró la Conferencia Mundial de Mujeres de las Naciones Unidas en Beijing que plasmó como objetivo estratégico la plena participación de las mujeres en las estructuras de poder y en la toma de decisiones y en la que se alentaba a los Estados a adoptar medidas, incluso en los sistemas electorales, que fomentaran la incorporación de mujeres en los puestos públicos en la misma proporción y en las mismas categorías que los hombres.

En el marco de esta Conferencia, la Unión Interparlamentaria preparó en 1994 un Plan de Acción donde se recogía la siguiente visión de la democracia:

El concepto de democracia sólo asumirá un verdadero y dinámico significado cuando los partidos políticos y las legislaciones nacionales sean decididas conjuntamente por hombres y mujeres teniendo en cuenta de forma equitativa los intereses y aptitudes de las dos mitades de la población.

En relación con los partidos políticos, se recomendaba el establecimiento de acciones afirmativas para incluir a las mujeres en los cargos orgánicos de decisión. Las mujeres socialistas que dirigían entonces el Instituto de la Mujer y las responsables de las políticas de igualdad en el Ministerio de Asuntos Sociales tuvieron un papel protagonista en la preparación de esta Conferencia. En ese mismo año, presidiendo España la UE, fue aprobado el IV Plan de Acción de la Unión Europea sobre la Igualdad de Oportunidades (1996-2000) que instará a los Estados miembros a adoptar medidas legislativas para hacer efectiva la igualdad (Jenson y Valiente, 2000: 100).

Por otro lado, en 1996, en su XVI Congreso en Nueva York la ISM exigía a los partidos miembros de la IS que aumentaran hasta el 50 por ciento la representación de mujeres en los órganos de toma de decisión y afirmaba: "Los partidos que no democratizan la proporción entre hombres y mujeres no son verdaderamente democráticos". El PSOE empezó a preparar la reforma de la LOREG en 1997 pero no fue finalmente presentada sino hasta noviembre de 1999. La presentación de la propuesta se retrasó 
porque se buscaba "abrir el debate a la sociedad" y porque se recabaron varios informes jurídicos sobre su constitucionalidad, intentando evitar lo sucedido en Francia en 1982 y en Italia en 1995 donde los respectivos Tribunales Constitucionales anularon las leyes de promoción femenina por considerar que violaban el principio de igualdad ante la ley. En mayo de 1999, la propuesta de democracia paritaria recibía el respaldo de la Coordinadora Española para el Lobby Europeo de Mujeres (CELEM) en un congreso internacional organizado en torno a esta cuestión con la participación de mujeres políticas y académicas procedentes de varios países de la UE (CELEM, 1999). Así, las mujeres socialistas podían presentar nuevos avales y apoyos para exigir la paridad en su partido.

Resultó también clave el respaldo de la dirección del partido para lograr extender su aplicación a toda la organización. Desde la dirección federal del PSOE se ha desarrollado un constante trabajo de supervisión del respeto a la cuota sobre los ámbitos territoriales inferiores. Todas las mujeres socialistas entrevistadas han confirmado el apoyo a las cuotas y al aumento de la presencia de la mujer recibido por las diferentes direcciones, desde Felipe González a J. L. Rodríguez Zapatero, pasando por Joaquín Almunia ${ }^{29}$. Apoyo sin duda necesario para vencer las resistencias de algunos compañeros de partido reticentes a la discriminación positiva. En la Conferencia Política celebrada en 2001 la dirección del PSOE presentaba el compromiso con la democracia paritaria como un ejercicio de pedagogía política:

La participación activa de las mujeres en la política, además de ser una exigencia de justicia, supone una ampliación de los recursos humanos potenciales que el Partido Socialista y la sociedad española deben aprovechar (...). La profundización en la democracia participativa significa profundizar en la democracia paritaria de una forma real, incorporando la visión del mundo y de la vida de las mujeres a la Política, por ello es necesario que toda la organización se comprometa a aumentar la afiliación de mujeres y que se establezcan pautas de funcionamiento que supongan un mayor acceso de la mujer en la participación dentro del seno de nuestro partido (...), dando ejemplo de esta forma al aplicarnos a nosotros mismos los principios cuya extensión al conjunto de la sociedad postulamos (PSOE, 2001b: 7).

Son varios los factores que podrían explicar el mayor éxito de la cuota en el PSOE que en IU. En primer lugar, la insistencia en la formación de las mujeres socialistas puede haber facilitado su incorporación en la Ejecutiva al desactivar el "argumento del mérito" defendido por algunos compañeros de partido. Por otro lado, dada la existencia de varias corrientes en IU que concurren a las elecciones internas en las que el resultado refleja una proporcionalidad pura, el número de mujeres puede verse reducido ya que los primeros puestos de las listas suelen estar copados,

29. Isabel Martínez, ex coordinadora de la Secretaría de Igualdad, entrevista personal, $18 / 11 / 04$. 
en general, por hombres. Esto es, a mayor competición entre candidatos, menor presencia de las mujeres en dichos órganos. La presentación de varias candidaturas para la Coordinación General afecta de forma negativa a la presencia de las mujeres puesto que la configuración de órganos de consenso que integren a miembros de todas las candidaturas termina por primar la presencia de los hombres. Así, en la Comisión Permanente de IU tras la VI Asamblea Federal (2000), oportunidad en la cual compitieron sólo dos listas alternativas, se observa un dramático descenso de las mujeres, pasando del 47 por ciento al 32 por ciento en la VIII Asamblea Federal (2004), cuando concurrieron tres candidatos. Otras explicaciones podrían apuntar a que en el PSOE esta disposición ha permeado en mayor medida en los distintos niveles territoriales que en el caso de IU ${ }^{30}$. Por último, los malos resultados electorales de IU desde 1999 pueden haber conllevado una mayor valoración de los cargos orgánicos al ser escasa la disponibilidad de cargos públicos.

La literatura ha sostenido tradicionalmente que es necesario que exista un mínimo, una "masa crítica" de mujeres antes de que éstas puedan desarrollar una identidad de grupo y una resistencia frente a la presión por socializarse dentro de los comportamientos masculinos establecidos (Threlfall, 1990: 223). Sin embargo, el PP ya dispone hace tiempo de esa masa crítica y el resultado no ha sido el que la teoría podría predecir. Habría que introducir pues otros elementos: la existencia de una "masa crítica" de mujeres con conciencia de grupo y con voluntad de constituirse como tal junto al apoyo de los dirigentes a la existencia de un lobby de mujeres en el partido. Con todo, ha resultado clave la presión que algunas mujeres afines al PP, como las afiliadas de Mujeres para la Democracia, han ejercido para elevar la representación de las mujeres populares. Estas últimas no se han constituido como lobby dentro del partido, pero su participación en conferencias internacionales de mujeres y, seguramente, su misma condición de mujer, aun compartiendo el rechazo a la cuota legal, ha hecho que también adoptaran el objetivo de incrementar su presencia tanto a nivel orgánico como público.

\section{Conclusiones}

La introducción de las cuotas y la importante presencia de las mujeres en la vida política en la actualidad no pueden entenderse sin el análisis de los debates producidos en los partidos en las dos últimas décadas. El incremento significativo de mujeres en puestos de responsabilidad polí-

30. Entre los representantes elegidos en la Asamblea Federal para el CPF siempre hay más mujeres que entre los designados por las federaciones. Por ejemplo, en la VIII Asamblea Federal (2004) los porcentajes fueron del 43 por ciento de mujeres en los candidatos designados por la Asamblea frente al 28 por ciento entre los representantes de las federaciones. Es decir, el respeto a la cuota es más efectivo en el nivel federal. 
tica no tuvo lugar hasta la década de los noventa, a pesar de que esta demanda estaba presente en la agenda feminista desde finales de los setenta. Las estrategias discursivas puestas en marcha por las Secretarías de Mujer de los partidos de izquierda resultaron fundamentales como paso inicial para la incorporación de las mujeres a los puestos de responsabilidad política al redefinir los temas "de mujer" como demandas por la igualdad entre géneros y al presentar la infrarrepresentación femenina como un déficit democrático.

Los partidos de izquierda tenían en los años ochenta y principios de los noventa fuertes incentivos para implementar aquellas políticas que contribuyesen a cambiar la dirección del voto conservador de una parte importante de las mujeres. En este marco se entiende el compromiso con la cuota de género. Así, se observa que la introducción de la cuota y la elevación sucesiva del porcentaje reservado a las mujeres discurren en paralelo en el PSOE y en IU. En 1988 el PSOE introduce la cuota del 25 por ciento que un año más tarde se aprobaría en IU. En 1990 IU eleva el porcentaje al 35 por ciento y en 1994 el PSOE establecía que cuando la afiliación femenina fuera mayor del 25 por ciento la cuota sería de 5 puntos por encima del porcentaje de afiliación. En 1997 los dos partidos adoptan la democracia paritaria fijando un mínimo del 40 por ciento y un máximo del 60 por ciento para cada uno de los géneros, el PSOE en su Congreso de junio e IU en la Asamblea de diciembre. Sin embargo, a partir de los años noventa, es el PP el que se ve compelido a hacer un guiño al electorado femenino porque su ventaja comparativa de género en el voto se había visto muy recortada. De este modo, la competición electoral entre los partidos ha resultado clave en el incremento de la representación femenina.

No obstante, la ideología del partido ha sido determinante en este proceso. La discriminación positiva no ha encajado en el pensamiento político popular ya que el PP considera que la elegibilidad para un cargo no puede basarse en otro criterio distinto del mérito o de la capacidad y que las características del representante no alteran el contenido ni la calidad de la representación. En cambio, los partidos de izquierda han otorgado a la representación paritaria no sólo un alto contenido simbólico basado en el argumento de la justicia y en el argumento del rol, sino que también han insistido en resaltar que la responsabilidad compartida del poder genera decisiones más legítimas, elevando la representación paritaria a condición sine qua non del fortalecimiento de la democracia. En estos partidos, el apoyo de la dirección a la discriminación positiva y a la constitución de lobbies de mujeres ha sido firme.

Por último, las Secretarías de Mujer fueron ganando mayor poder orgánico con el paso del tiempo. La creciente tasa de afiliación femenina y las campañas realizadas por distintas organizaciones nacionales e internacionales a favor de la cuota fueron las principales cartas con las que 
pudieron contar las mujeres de los partidos de izquierda para ganar la partida a aquellos compañeros que todavía albergaban dudas sobre la necesidad de terminar con una discriminación histórica que no se correspondía con el nivel cultural y económico que las mujeres habían alcanzado en las últimas décadas.

\section{Bibliografía}

Astelarra, Judith. 2005. Veinte años de políticas de igualdad. Cátedra: Valencia.

Baón, Rogelio. 2001. Historia del Partido Popular. Del franquismo a la refundación. Vol. I, Madrid: Ibersaf.

Camps, Victoria. 1998. "La otra gramática del poder". Leviatán 71: 41-51. Número dedicado a "Feminismo: derecha e izquierda".

Coordinadora Española para el Lobby Europeo de Mujeres. 1999. Hacia una democracia paritaria: análisis y revisión de las leyes electorales vigentes. Madrid: CELEM.

Craig, Patricia. 1995. "Political mediation, traditional parties and new social movements: lessons from the Spanish Socialist Worker's Party". Estudio/ Working Paper 1995/67. Madrid: CEACS, Instituto Juan March.

Farrell, David M. 2001. Electoral systems. Nueva York: Palgrave.

Fernández Felgueroso, Paz. 1990. "Las propuestas del socialismo y el feminismo sobre la participación política de las mujeres". En Participación política de las mujeres, editado por J. Astelarra. Madrid: CIS, 193-200.

García Escribano, Juan José y Frutos, Lola. 1999. “Mujeres, hombres y participación política. Buscando las diferencias". Revista Española de Investigaciones Sociológicas 86: 307-329.

Instituto de la Mujer. 1999. La situación de la mujer en la toma de decisiones. Madrid: Instituto de la Mujer.

2004. Mujeres en cifras. http: / / www.mtas.es/mujer

Internacional Socialista de Mujeres. 1996. XVI Congreso. La Igualdad en el Nuevo Milenio.

liderazgo y estrategias.

1998. Reunión del Buró, Oslo. Las mujeres y el poder compartido: 2000. Reunión del Buró, Bruselas. Democracia paritaria: gobernando juntos por una cultura de la paz.

Izquierda Unida. 1986: Elecciones Generales 1986. "El compromiso de IU con la sociedad española".

1989. Resoluciones I Asamblea Federal. Febrero de 1989.

1990. Resoluciones II Asamblea Federal. Noviembre de 1990.

1992. Resoluciones III Asamblea Federal. Mayo de 1992. 
1999. Programa Elecciones Municipales 1999. "Compromisos para avanzar por la izquierda".

. 2003. Resoluciones VII Asamblea Federal. Diciembre de 2003.

. 2004. Programa Elecciones Generales 2004. "Palabra".

Jenson, Jane y Valiente, Celia. 2001. “El movimiento a favor de la democracia paritaria en Francia y España". Revista Española de Ciencia Política 5: 79-110.

Lovenduski, Joni y Norris, Pippa (eds.). 1993. Gender and Party Politics. Thousand Oaks, California: Sage.

Lovenduski, Joni. 1993. "Introduction: the dynamics of gender and party". En Gender and Party Politics, editado por J. Lovenduski y P. Norris. Thousand Oaks, California: Sage, 1-15.

Nasarre, Eugenio. 2002. "Las 'listas cremallera' y la democracia representativa”. El País, 28 de junio de 2002.

Norris, Pippa. 1993. "Conclusions: comparing legislative recruitment". En Gender and Party Politics, editado por J. Lovenduski y P. Norris. Thousand Oaks, California: Sage, 309-330.

Panebianco, Angelo. 1990. Modelos de partido. Organización y poder en los partidos políticos. Madrid: Alianza.

Partido Comunista de España. 1977. Programa Elecciones Municipales 1977.

1978. Resoluciones IX Congreso Federal. Abril de 1978. “Un debate comunista para la democracia y el socialismo".

$$
\begin{aligned}
& \text { —__ 1979. Programa Elecciones Municipales } 1979 . \\
& \text { ___ 1981. Resoluciones X Congreso Federal. Julio de } 1981 . \\
& \text { ___ 1983a. Programa Elecciones Municipales } 1983 . \\
& \text { __. 1983b. Resoluciones XI Congreso Federal. Noviembre de } 1983 .
\end{aligned}
$$

Partido Popular. 1996a. Resoluciones XII Congreso Nacional. Enero de 1996. "Gana el centro".

1996b. Programa Elecciones Generales 1996. "Con la nueva mayoría".

. 1999. Resoluciones XIII Congreso Nacional. Enero de 1999. “El proyecto para un nuevo siglo. La España de las oportunidades".

—_. 2002a. Resoluciones XIV Congreso Nacional. Enero de 2002. “Un nuevo impulso para España".

\footnotetext{
-_. 2002b. Las propuestas del centro. Un nuevo impulso para España.

___ 2004a. Programa Elecciones Generales 2004. "Avanzamos juntos".

___ 2004b. Nuestro partido hoy (documento facilitado en el XV Congreso). Ponencias. "Comprometidos con las personas".
}

Partido Socialista Obrero Español. 1979. Resoluciones XXVIII Congreso Federal. Mayo de 1979. "Construir en libertad". 
1981. Resoluciones XXIX Congreso Federal. Octubre de 1981. "Raíces para la democracia".

1984. Resoluciones XXX Congreso Federal. Diciembre de 1984. "Compromiso con la solidaridad".

1985. Las mujeres y los gobiernos: querer y poder. Madrid: PSOE, Secretaría de Participación de la Mujer.

1986. Programa Elecciones Generales 1986. "Por buen camino".

el futuro".

1988a. Resoluciones XXXI Congreso Federal. Enero de 1988. “Ganar

___ 1988b. Informe de Gestión de la CEF (1984-1988), presentado en el XXXI Congreso Federal, 1988.

—_. 1988c. 100 años de Congresos, 1888-1988. Madrid: PSOE.

___ 1989. Programa Elecciones Generales 1989.

___ 1990. Resoluciones XXXII Congreso Federal. Noviembre de 1990. "En una nueva sociedad".

—_ 1993. Programa Elecciones Generales 1993. "El programa de la mayoría".

___ 1994a. Resoluciones XXXIII Congreso Federal. Marzo de 1994. “Un nuevo impulso del socialismo".

- 1994b. Informe de Gestión de la CEF (1990-1994), presentado en el XXXIII Congreso Federal, 1994.

___ 1996. Programa Elecciones Generales 1996. "España en positivo".

___ 1997. Resoluciones XXXIV Congreso Federal. Junio de 1997. “La respuesta progresista".

- 1998. La participación de las mujeres en el PSOE y en las Instituciones Públicas. Madrid: PSOE, Secretaría de Igualdad.

. 2000. Programa Elecciones Generales 2000. "España como tú la harías".

. 2001a. La participación de las mujeres en el PSOE y en las Instituciones Públicas. Madrid: PSOE, Secretaría de Igualdad.

y Socialismo.

2001b. Conferencia Política. 2001. Resoluciones: Ciudadanía, Libertad

2002. I Plan de Igualdad. Madrid: PSOE, Secretaría de Igualdad.

compromiso"

2004a. Resoluciones XXXVI Congreso Federal. Julio de 2004. “El mejor".

2004b. Programa Elecciones Generales 2004. “Merecemos una España

Phillips, Anne. 1998. “Democracy and representation: or, why should it matter who our representatives are?". En Feminism and politics, editado por A. Phillips. Nueva York: Oxford University Press, 224-240.

Ramiro, Luis. 2004. Cambio y adaptación en la izquierda. La evolución del Partido Comunista de España y de Izquierda Unida (1986-2000). Madrid: CIS. 
Renau, María Dolors. 1998. "Feminismo: derecha e izquierda". Claves de la Razón Práctica 80: 70-75.

Ruiz Jiménez, Antonia M. 2002. Mecanismos del cambio ideológico e introducción de políticas de género en partidos conservadores: el caso de AP-PP en España en perspectiva comprada. Madrid: CEACS, Fundación Juan March. Tesis doctoral.

Ryder, David K. 1996. Representation in crisis. Albano, Nueva York: State University of New York Press.

Sánchez Ferriz, Remedio. 2000. "Las mujeres en las Cortes Generales y en los Parlamentos de las Comunidades Autónomas". En Mujer y Constitución en España, AA.VV. Madrid: Centro de Estudios Políticos y Constitucionales, 203-234.

Sánchez Hernández, María F.2003. Liderazgo político de mujeres. Desde la transición hasta las cuotas. Sevilla: Instituto Andaluz de la Mujer.

Threlfall, Mónica. 1990. “¿Patriarca, palanca, paraguas? Planteamientos feministas en torno al estado asistencial". En Participación política de las mujeres, editado por J. Astelarra. Madris: CIS, 215-233.

. 1996. "Femisist politics and social change in Spain". En Mapping the women's movement, editado por M. Threlfall. Londres: Verso - New Left Review, $115-151$.

Uriarte, Edurne. 1995. “Mujer y política en España”, Sistema 124: 121-136.

1997. "Las mujeres en las élites políticas", En Mujeres en política. Análisis y práctica, coordinado por E. Uriarte y A. Elizondo. Barcelona: Ariel, 1532.

Verge, Tània. 2005. Partidos y representación política: las dimensiones del cambio en los partidos políticos españoles, 1977-2004. Tesis doctoral. Madrid: Instituto Universitario de Investigación Ortega y Gasset- Universidad Complutense.

Young, Iris M. 2000. Inclusion and democracy. Oxford: Oxford University Press. 
$\perp^{\prime}$

$1 L$

$\overline{7}$

$\mid \overline{\bar{F}}$ 